\title{
Preparation of Pellets Containing Highly Soluble Drug by Extrusion/Spheronisation and Coating with Kollicoat ${ }^{\circledR}$ SR 30D
}

\author{
Itamar Francisco Andreazza ${ }^{1 *}$ and Humberto Gomes Ferraz ${ }^{2}$ \\ ${ }^{1}$ Departamento de Farmácia; Universidade Federal do Paraná; Av. Lothário Meissner, 632; Curitiba - PR - Brasil. \\ ${ }^{2}$ Departamento de Farmácia; Universidade de São Paulo; São Paulo - SP - Brasil
}

\begin{abstract}
The aim of this study was to prepare and evaluate the pellets, containing a highly soluble drug (ascorbic acid), by the extrusion-spheronization process and coated with a release controlling polymer. The coating (undertaken in a fluid bed) was applied to three batches of the pellets with a dispersion of Kollicoat ${ }^{\circledR}$ SR 30 D, with each batch of pellets receiving a different level of polymer (5.07; 8.26 and 10.35\%). The coated pellets were evaluated for sphericity by imaging analysis and comparative dissolution profile with a product commercially available in Brazil. All of the evaluated samples presented adequate physical properties and the dissolution profile of those coated with $5.07 \%$ of polymer proved to be similar to that of the commercially available brand name.
\end{abstract}

Key words: coating - pellets - extrusion spheronization - controlled release

\section{INTRODUCTION}

Among the different possibilities for the oral administration of pharmaceutical drugs, pellets have garnered much attention due to their inherent technological and therapeutical advantages, such as efficient absorption and distribution via the gastro-intestinal tract, decreased risk of localized irritation and their spherical format, which makes coating for the controlled release of active agents easier, among other things (Newton et al., 2002; Ford et al., 2003; Siepmann et al., 2004).

Generally, controlled-release pellets are prepared by coating an inert nucleus first with an atomized solution or suspension containing the active agent of the drug and then with the substances that can control its dissolution process. A second method consists of the preparation of pellets containing a drug, which are then coated with an aqueous polymer dispersion, in a single uniform layer of film. In the latter case, the drug is inserted into a nucleus which is then coated with a porous layer responsible for controlling the speed of dissolution (Nastruzzi et al., 2000; Ford et al., 2003).

The coating of solid dosage forms with the application of aqueous or organic polymer dispersions is a well-known procedure in the pharmaceutical industry. However, toxicity, environmental concerns and shorter processing times all mean that aqueous dispersions are more commonly used (Dashevsky et al., 2005).

The formation of a uniform, rupture-less film created from an aqueous dispersion basically depends on the polymer used and the minimum

*Author for correspondence: itamar@ufpr.br 
film-forming temperature - MFT (Siepmann et al., 2006). Dosage forms coated in polymers with elevated MFT values generally undergo thermal treatment for short periods of time, called the "curing" process, so that the complete coalescence and formation of the film may occur. Plasticizers are often added to these dispersions in order to reduce MFFT values and improve the formation of the film. However, the curing process and the addition of plasticizers may alter the dissolution profile of the drug (Bodmeier and Paeratakul 1994).

Kollicoat ${ }^{\circledR}$ SR 30D is a commercial alternative that enables solid dosage forms to be coated without the material having to undergo the curing process and without the addition of plasticizers to the formula (Dashevski et al., 2005). Shao et al. (2002) prepared controlled-release pellets by coating the inert nuclei with a Kollicoat ${ }^{\circledR}$ SR 30D dispersion associated to the drug (diphenhydramine hydrochloride). The dissolution profile presented an effective control over the release of the drug. By combining Kollicoat ${ }^{\circledR}$ SR 30D and Kollicoat $^{\circledR}$ MAE (enteric release dispersion) in a 90:10 proportion to coat verapamil hydrochloride pellets, Dashevski et al., (2004) demonstrated that $\mathrm{pH}$-independent release was possible for this drug. Dashesvki et al. (2005) evaluated three drugs (ibuprofen, propranolol and ambroxol hydrochloride) and reported the physical and chemical characteristics of Kollicoat ${ }^{\circledR}$ SR 30D in film formation without the addition of a plasticizer, in addition to its flexibility in the development of controlled-release dosage forms. Gehbre-Sellassie et al. (1988) found that the aqueous solubility of a drug was an important parameter that needed to be evaluated during the preparation of coated controlled-release pellets, because highly soluble drugs were generally released faster than those with lower solubility in water, which presented a great challenge for the formulator.

The aim of this study was to evaluate the use of Kollicoat $^{\circledR}$ SR 30 D, a polyvinylacetate-based commercial product, in the coating of the pellets obtained by the extrusion-spheronization process containing a highly soluble drug (ascorbic acid), and to determine the level of coating necessary to achieve an adequate level of control over the release of the drug.

\section{MATERIAL AND METHODS}

Pharmaceutical-grade raw materials were obtained from the local suppliers and were used as received. The pellets were prepared with 101 microcrystalline cellulose- Microcel $^{\circledR} \quad 101$ (Blanver, Cotia, Brazil), tartaric acid, polyvinylpyrrolidone $\mathrm{K} 30$ and ascorbic acid (Synth São Paulo, Brazil). The aqueous dispersion of Kollicoat ${ }^{\circledR}$ SR 30 D was kindly donated by BASF S.A. (São Paulo, Brazil). As a reference product, commercially available pellets (C) containing ascorbic acid packed in hard gelatin capsules was obtained (Cebion - batch 1041181A, Merck SA, Brazil).

\section{Pellet preparation}

The pellets were prepared (50.96\% Microcel $^{\circledR} 101$, $10.22 \%$ polyvinylpyrrolidone $\mathrm{K} 30,0.6 \%$ tartaric acid, $38.22 \%$ ascorbic acid and purified water $35 \mathrm{~mL} \%$ ) by the extrusion- spheronization process (Extruder 20, Caleva, Dornset, UK), spheronized (Spheronizer 250, Caleva, Dornset, UK) into 25 $\mathrm{cm}$-diameter cross-hatch pattern discs at $1000 \mathrm{rpm}$ for 10 minutes. The pellets were dried in a Hüttlin Mycrolab fluid bed (Hüttlin, Steinen, Germany) for 30 minutes. Then the material obtained was sorted by five sequential sieves (Bashaiwoldu et al., 2004). The fraction covering the interval from 0.5 to $1.4 \mathrm{~mm}$ was separated into two sections, the first called uncoated pellets (UC) and the second chosen for coating.

\section{Coating of pellets}

Three batches of $50 \mathrm{~g}$ pellets (K1, K2 and K3) were coated by atomizing the dispersion of $68.8 \%$ Kollicoat ${ }^{\circledR}$ SR 30 D (27\% polyvinyl acetate, $2.7 \%$ povidone and $0.3 \%$ de sodium lauryl sulfate), $1.55 \%$ talc, $0.23 \%$ titanium dioxide and $29.42 \%$ purified water for 45 minutes for K1, 90 minutes for K2 and 160 minutes for K3. The coating was done in a Hüttlin Mycrolab fluid bed (Hüttlin, Steinen, Germany) with air input and output temperatures of $50.9^{\circ} \mathrm{C}$ and $33.5^{\circ} \mathrm{C}$, respectively, air flow of $17.5 \mathrm{~m}^{3} / \mathrm{h}$, product temperature of $35^{\circ}$ $\mathrm{C}$, and atomization pressure of $1 \mathrm{bar}$, needle $\mathrm{n}^{\circ} .6$ and peristaltic pump speed of $1.1 \mathrm{~mL} / \mathrm{min}$. At the end of each process, the pellets were dried for fifteen minutes in the same equipment and conditions. 


\section{Imaging analysis}

Samples of UC and K1, K2 and K3 pellets were analyzed by a JEOL JSM-6360 LV scanning electron microscope (Tokyo Japan) for a surface evaluation (before and after coating). Samples from the same batches were also examined with a CCD Olympus SZ stereo microscope (Olympus America Inc., New York, USA). The digital images were processed by the software Image proplus $^{\circledR}$ (version 1.2, Media Cybernetics, Silver Spring, MD, USA), where the perimeter, the average, minimum and maximum diameters were ascertained (used in the determination of sphericity or shape factor $e_{\mathbf{R}}$ described by Podczeck et al., 1999), as well as the ratio radius.

\section{Ascorbic acid content}

The ascorbic acid content for the different batches was ascertained (sample of $100 \mathrm{mg}$ ) by high performance liquid chromatography-HPLC (Varian, Palo Alto, USA), mobile phase (90\% of $0.2 \%$ metaphosphoric acid in purified water, $8 \%$ methanol and $2 \%$ acetonitril, all of chromatographic grade), column C18, $5 \mu \mathrm{m}, 250 \mathrm{x}$ $4.6 \mathrm{~mm} ; 20 \mu \mathrm{L}$ looping, UV-VIS Prostar 320 detector $^{\circledR}$ and data handled by Workstation Star $6.0^{\circledR}$.

\section{Evaluation of the coating}

The level of coating for each batch was calculated by subtracting the ascorbic acid content determined in the coated pellets from that ascertained for the uncoated pellets (Amighi and Moës, 1996).

\section{Dissolution profile}

The dissolution profile of the UC, K1, K2, K3 and $\mathrm{C}$ pellets was carried out in the Erweka DT80 (Erweka GmbH, Bizen, Germany) dissolution tester, equipped with an apparatus 1 (basket) rotating at $100 \mathrm{rpm}$. The dissolution medium consisted of $900 \mathrm{ml}$ of $0.1 \mathrm{M}$ hydrochloric acid for the first hour of the test. For the subsequent five hours, a $0.06 \mathrm{M}$ phosphate buffer $(\mathrm{pH}$ 6.8) was used as a dissolution medium. Samples of $10 \mathrm{ml}$ were drawn after 1, 5, 10, 20, 40, 60, 120, 180, 240, 300 and 360 minutes, filtered (Millipore HV JBR610245-Millipore, Massassuchets, USA), and then underwent HPLC using the aforementioned conditions. The profiles obtained were compared by the determination of the factors of similarity and difference $\left(f_{2}\right.$ and $\left.f_{1}\right)$, with the commercially available product, $\mathrm{C}$, as a reference (Guidance, 1997).

\section{RESULTS AND DISCUSSION}

The shape of the pellets was evaluated by the ratio radius and the parameter $e_{R}$, whose value of 0.6 was the minimum limit to describe a particle with good sphericity, which corresponded to a maximum ratio between radii of 1.1 (Podczeck and Newton 1994 and 1995; Podczeck et al., 1999). However, according to Vervaet and Remon (1996), this value should be less or equal to 1.2.

The sphericity values for UC (Table 1) were lower than that indicated; however they were apt to be coated (Fig. 1). For the batches K1, K2 and K3, a gradual increase in the $e_{R}$ value was noted (Table 1 ), accompanied by the reduction in the ratio radius, indicating a possible improvement in the sphericity with increase of the roughness (Fig.1).

This behavior could be linked to the fluid bed coating process, which resulted in a rounding of the particles due to the uniform deposition of the film, thus correcting the imperfections of the spheronization process. The advent of roughness could be linked to the fluid bed coating process and the length of time that each batch was submitted to the process. In these apparatuses, solvent evaporation occurs rapidly. Dyer et al. (1994) noted that processes of this nature led to greater roughness on the surface of the pellets.

Table 1 - Values of the ratio radius and sphericity $\left(e_{R}\right)$ of the pellets $\mathrm{UC}, \mathrm{K} 1, \mathrm{~K} 2, \mathrm{~K} 3$ and C

\begin{tabular}{lccccc}
\hline & $\mathbf{U C}$ & $\mathbf{K 1}$ & $\mathbf{K 2}$ & $\mathbf{K 3}$ & $\mathbf{C}$ \\
\hline Ratio radius & $1,13 \pm 0,05$ & $1,12 \pm 0,17$ & $1,08 \pm 0,20$ & $1,10 \pm 0,04$ & $1,04 \pm 0,01$ \\
$\mathbf{e}_{\mathrm{R}}$ & $0,55 \pm 0,07$ & $0,56 \pm 0,09$ & $0,60 \pm 0,05$ & $0,61 \pm 0,09$ & $0,66 \pm 0,05$ \\
\hline
\end{tabular}




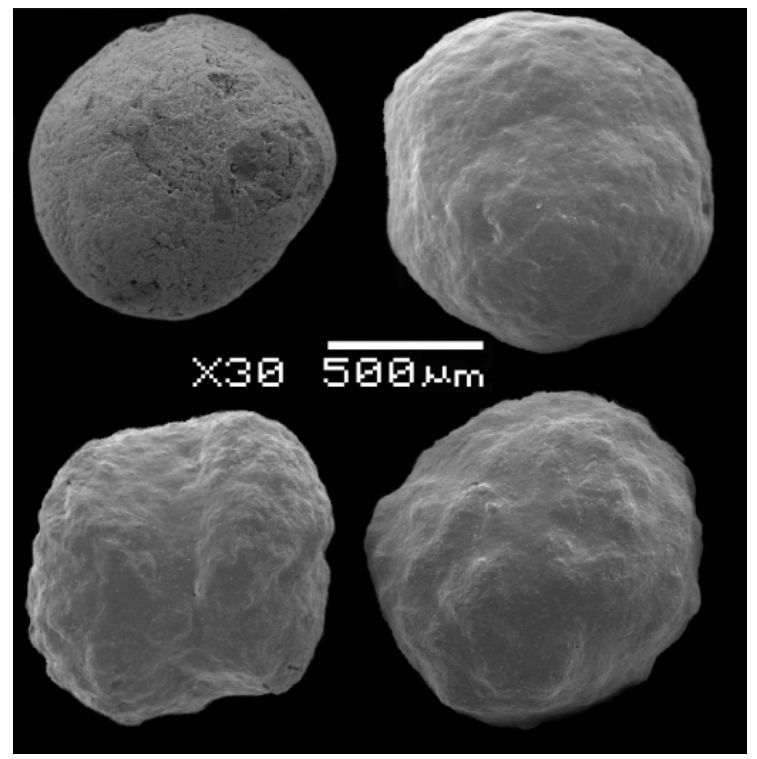

Figure 1 - Image analysis (SEM-25keV) of the surface of the pellets UC, K1, K2 e K3.

Thus, the pellets in which the coating time was higher remained under the influence of the air flow and the temperature of the process for a longer period of time, which led to a "shrinkage" of the coating layer. According to Amighi and Moës (1996), the content of the drug present in the uncoated dosage form is a reference to ascertain the level of coating of the coated version of the same dosage form. The values described in Table 2 demonstrated a reduction in the ascorbic acid content in the $\mathrm{K} 1, \mathrm{~K} 2$ and $\mathrm{K} 3$ sequence, indicating a proportionately growing layer of coating. This outcome was expected, since the coating times were different for all of the batches $(45,60$ and 160 minutes, respectively). For the UC pellets, the dissolution was higher than $80 \%$ in the first 15 minutes of the test, a characteristic of readyrelease products.

In the $\mathrm{K} 1, \mathrm{~K} 2$ and $\mathrm{K} 3$ batches, coated with Kollicoat ${ }^{\circledR}$ SR 30 D, there was an alteration in the dissolution profile compared to UC, demonstrating the influence of the polymer layer in the dissolution of the drug. The reduction in the percentage of ascorbic acid dissolved was proportional to the level of coating (Fig. 2), where the batches with a higherlayer of coating presented lower drug dissolution, exactly what was described by Shao et al., (2002) and Bodmeier and Pearnchob (2003) and Dashevsky et al., (2004).

For the commercially available product $\mathrm{C}$, the dissolution profile ascertained was compatible with a controlled-release dosage form. The comparison the dissolution profiles of $\mathrm{K} 1$ and $\mathrm{C}$ presented very similar values of dissolved percentage point by point, differing only in the initial collection times of the test (up to time number 40), where K1 presented higher retention of the drug. Through the determination of the factors of difference $\left(f_{2}\right)$ and similarity $\left(f_{1}\right)$ (Table 2 ), the proximity between these profiles was evident (Guidance, 1997). Thus, the $5.07 \%$ level of coating used in K1 was sufficient and adequate to control the release of ascorbic acid as it presented a dissolution profile compatible with the commercial product, which enabled a gradual release over a long period of time.

Table 2 - Values of the ascorbic acid content of the pellets UC, K1, K2 and K3, their levels of coating, similarity and difference factors $\left(f_{1}\right.$ and $\left.f_{2}\right)$ among dissolution profile $\mathrm{K} 1, \mathrm{~K} 2$ e K3

\begin{tabular}{lcccc}
\hline & UC & K1 & K2 & K3 \\
\hline Ascorbic acid content (mg\%) & $37.45 \pm 0.57$ & $32.38 \pm 2.27$ & $29.19 \pm 1.73$ & $27.10 \pm 0.85$ \\
Coating level (mg\%) & - & 5.07 & 8.26 & 10.35 \\
$\mathrm{f}_{1}$ & - & 13.52 & 67.25 & 93.22 \\
$\mathrm{f}_{2}$ & - & 62.05 & 28.83 & 20.88 \\
\hline
\end{tabular}




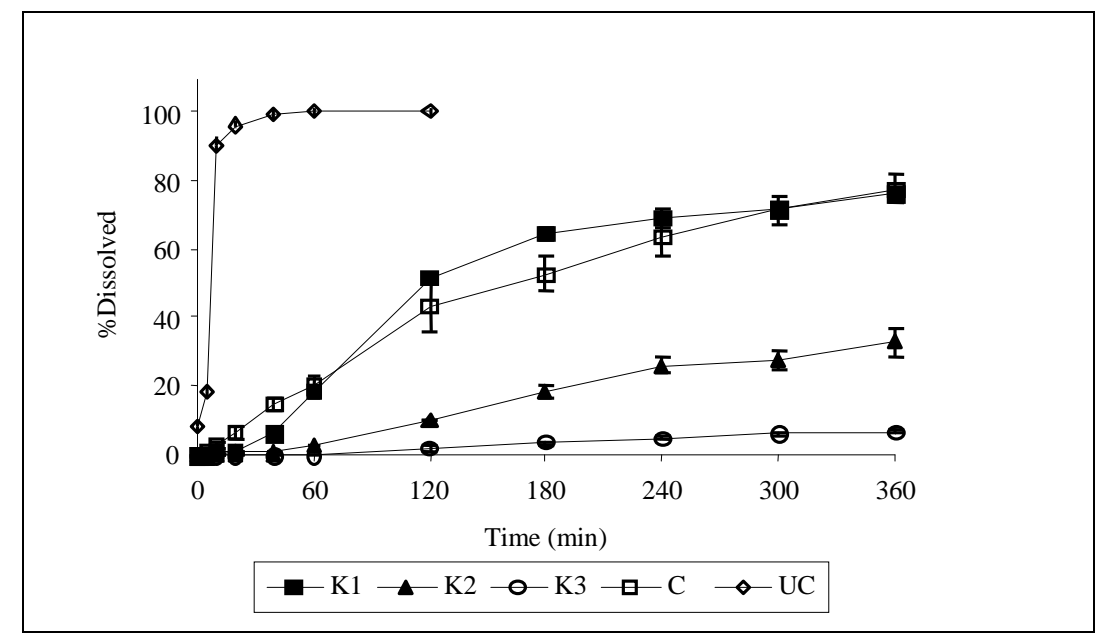

Figure 2 - Dissolution profile of pellets K1, K2, K3, C and UC.

\section{CONCLUSION}

The use of the dispersion of Kollicoat ${ }^{\circledR}$ SR 30 D in the coating of the pellets containing ascorbic acid resulted in effective control over the release of the drug. An approximately 5\% level of coating was necessary for this. In these conditions, the pellets produced by the extrusion/spheronization process were apparently similar, in terms of dissolution of ascorbic acid, to the commercially available reference product.

The amount of drug dissolved was directly related to the level of coating applied, as evidenced by the performance of the batch with the highest level of coating (K3). This enabled the dissolution profile of drugs with high solubility in water to be modified by altering the thickness of the layer of coating without altering the release process mechanism.

\section{AKNOWLEDGMENTS}

We would like to thank the Laboratory of Electron Microscopy of UFPR and Laboratory Analysis of Rocks and Minerals (LAMIR-UFPR).

\section{REFERENCES}

Amighi, K, Möes, A. (1996), Influence of plasticizer concentration and storage conditions on the drug release rate from eudragit ${ }^{\circledR}$ RS30D film-coated sustained-release teophylline pellets. Eur. J. Pharm. Biopharm., 42, 29-35.
Bashaiwoldu, AB., Podczeck, F, Newton, JM. (2004), A study on the effect of drying techniques on the mechanical properties of pellets and compacted pellets. Eur. J. Pharm. Biopharm., 21, 119-129.

Bodmeier, R, Paeratakul, O.(1994)The distribution of plasticizers between aqueous and polymer phases in aqueous colloidal polymers dispersion. Int. J. Pharm., 103, 47-54.

Bodmeier, R, Pearnchob, N. (2003), Coating of pellets with miconized ethylcellulose particles by a dry powder technique. Int. J. Pharm., 268, 1-11.

Dashevsky, A, Kolter, K, Bodmeier, R. (2004), pH independent release of a basic drug from pellets coated with the extended release polymer dispersion Kollicoat $^{\circledR}$ SR 30 D and the enteric polymer dispersion Kollicoat ${ }^{\circledR}$ MAE 30 DP. Eur. J. Pharm. Biopharm., Amsterdam, 58, 1, 45-49.

Dashevsky, A, Wagner, K, Kolter, K, Bodmeier, R. (2005), Physiochemical and release properties of pellets coated with Kollicoat $^{\circledR}$ SR 30 D, a new aqueous polyvinylacetate dispersion for extended release. Int. J. Pharm., 290, 15-23.

Dyer, AM, Khan, KA, Aulton, ME. (1994), Effect of the drying method on the mechanical and drug release properties of pellets prepared by extrusionspheronization. Drug Dev. Ind. Pharm., Philadelphia, 20, 3045-3068.

Ford, JL, Sadeghi, F, Rajabi-Siahboomi, AR. (2003), The influence of drug type on the release profiles from surelease-coated pellets. Int. J. Pharm., 254, 123-135.

Gehbre-Sellassie, I, Preface. In: Multiparticulate oral drug delivery. New York: MarcelDekker, 1994.

GUIDANCE for industry: Supac-MR - Modified release solid oral dosage forms. FDA, 1997. http://www.fda.gov./cder/guidance/index.html> 
Nastruzzi, C, Cortesi, R, Esposito, E, Genovesi, A, Spadoni, CV, Menegatti, E (2000), Influence and process parameters on pellet production by powder layering technique. AAPS PharmSciTech. 1, article 9. http://www. Aapsphams citech.org.

Newton, J M, Chopra, R, Podczek, F, Alderborn, G. (2002), The influence of pellet shape and surface properties on the drug release from uncoated and coated pellets. Int. J. Pharm., 239, 171-178.

Podczeck, F, Newton, JM. (1994). A shape factor to characterize the quality of spheroids. J. Pharm. Pharmacol., 46, 82-85.

Podczeck, F, Newton, JM. (1995), The evaluation of a three-dimensional shape factor for the quantitative assessment of the sphericity and surface roughness of pellets. Int. J. Pharm., 124, 253-259.

Podczeck, F, Rhaman, SR, and Newton, JM. (1999), Evaluation of standardised procedure to assess the shape of pellets using image analysis Int. J. Pharm., 192, 123-128.
Shao, ZJ, Morales, L, Diaz, S, Muhammad, NA. (2002), Drug release from Kollicoat SR 30 D- coated nonpareil beads: evaluation of coating level, plasticizer type, and curing condition. AAPS Pharmscitech. 3, article 15. http://www.aapsphams citech .org

Siepmann, J, Lecomte, F, Walther, M, MacRae, RJ, Bodmeier, R. (2004), Polymer blends used for the aqueous coating of solid dosage forms: importance of the type of plasticizer. J. Cont. Rel., 99, 1-13.

Siepmann, F, Siepmann, J, Walther, M, MacRae, RJ. and Bodmeier, R. (2006), Aqueous HPMCAS coatings: Effects of formulation and processing parameters on drug release and mass transport mechanisms. Eur. J. Pharm. Biopharm., 63 (2), 262269.

Vervaet, C, Remon, JP. (1996), Influence of impeller design, method of screen of screen perforation geometry on the quality of pellets made by extrusionspheronisation. Int. J. Pharm., 133, 29-37. 